\title{
Study Subject Radiograph
}

National Cancer Institute

\section{Source}

National Cancer Institute. Study Subject Radiograph. NCI Thesaurus. Code C115561.

A radiographic image taken of a study participant for use in a clinical trial. 